\title{
Introducción al protocolo turístico-hotelero
}

\section{Introduction to protocol Tourist \& Hospitality}

\author{
Dr. D. Jorge J. Fernández y Vázquez, Ph.D., P.D. ${ }^{1}$ \\ UMHE/IMEP \\ jorgejfyv@me.com
}

Recepción: 11/11/15 Revisión: 12/11/15 Aceptación: 29/11/15 Publicación: 01/12/15

http:// (página web de inclusión del artículo)

\begin{abstract}
Resumen
El Protocolo Turístico y Hotelero una visión desde la perspectiva intercultural. Del Profesional del Turismo y Hotelería que ofrece los servicios del sector y del Profesional de Protocolo que necesita de los servicios del Sector Turístico.

Un Protocolo que tiene conexión con el Protocolo de Empresa.

¿Por qué el Protocolo en el sector Turístico? Por 5 razones importantes, y más especialmente en el Sector Hotelero.

El Protocolo en la empresa turística se establece desde 3 componentes.

Palabras clave: Protocolo Turístico, Hotelería, Sector, Empresa/negocio, Intercultural.
\end{abstract}

\section{Abstract}

The Tourism and Hospitality Protocol a view from an intercultural perspective. Professional Tourism and Hospitality offering services sector and Professional Protocol need the services of the Tourism Sector.

A protocol that has connection with the Business Protocol.

Why the Protocol on Tourism sector? For 5 important reasons, and especially in the Hospitality Industry.

The Protocol on the tourist business is set for 3 components.

\section{Keywords}

Protocol, Tourism, Hospitality, Industry, Business; Intercultural

\footnotetext{
${ }^{1}$ Profesor de Protocolo, RR.II. y Organización de Eventos de la UMH/IMEP. Profesor del Máster de Dirección y Gestión Hotelera del ICE/UPM. Fundador de Faculty Brokers International Consulting. Profesor del Máster universitario en Protocolo de la UNED.
} 
Vamos a ver un poco por a modo de introducción lo que es el Protocolo en las empresas de turismo, hotelería, ocio y recreación, que es algo que la gente suele confundir bastante porque cree que el Protocolo Turístico-Hotelero sólo es colocar platos, mesas, manteles, etc., y el protocolo hotelero es mucho más, es un mundo.

Todo el mundo sabe, por antecedentes históricos, lo que es el Protocolo: las reglas y costumbres protocolarias que sirven para normalizar cualquiera de las Instituciones y Gobiernos o a las personas mismas que los constituyen. Todo el mundo sabe también que el protocolo determina la precedencia así como el tratamiento y la equivalencia entre autoridades gubernamentales, diplomáticas, religiosas, militares, etc., pero también en el sector y empresas privadas, en este caso en el sector turístico u hotelero, que es un gremio muy particular. Nos guste o no, España es un país fundamentalmente turístico y ojalá siga siendo así, tal y como está la situación. Es el cuarto país del mundo en número de visitantes. Turísticamente hablando, más de 55 millones, por detrás de Francia, Estados Unidos y China, que son los que ganan, no en calidad de turismo pero sí en ese aspecto, y el turismo es una de las bases principales de la economía de España, que es la segunda nación del mundo con respecto a los ingresos per cápita en el sector por países.

El sector turístico es uno de los que más necesidad existe de practicar unas normas y unos principios que ayuden a dar la diferenciación, el valor agregado, que tiene que haber a la hora de tratar al cliente o tratar a la gente que participa del turismo.

Hay diferentes protocolos en el turismo. El protocolo aplicado al sector turístico proviene de dos facetas o caminos muy diferenciados: primero, del profesional del Turismo y Hotelería, que ofrece los servicios del sector, y segundo, del profesional de Protocolo que necesita de los servicios del sector turístico. Unos necesitan de nosotros y nosotros necesitamos de ellos hoy en día. Es un binomio, un tándem, un equipo de trabajo, que tiene la condición sine qua non de que debe ir en paralelo y nos necesitamos.

El protocolo empresarial aplicado al turismo interviene desde la imagen personal, pasando por la etiqueta (no la de pajarita, corbata, del chef o del metre o de las personas que trabajan en la hostelería en el hotel) de cada uno de los segmentos o del staff que 
intervienen en el Turismo: agencias de viajes, hotelería, resorts... Toda esa gente que trabaja como staff tiene que tener una etiqueta a la hora de ir uniformada o ir en esos aspectos con su presencia. También la cortesía, hasta la manera de gestionar las quejas. En Turismo hay algo muy importante: hay quejas por el servicio que damos, por lo que debe haber un protocolo de resolución de quejas. En Turismo es una condición sine qua non porque es complicado. No llueve a gusto de todos y es una de las pocas profesiones. Sin menospreciar las demás, que intentan que la gente sonría, que es lo que hace falta hoy en día. La gente sonríe porque se va de vacaciones, porque practica deporte... Es un segmento muy particular.

Para el Protocolo en el sector turístico hay cinco puntos importantes:

1. Porque es una poderosa herramienta a la hora de trabajar.

2. Porque cada día se enfrentan ustedes con consumidores mucho más conflictivos, más exigentes y más experimentados a la hora de pedir la calidad del servicio, por lo que hay que ir con mucho más tiento y hace falta un Protocolo muy medido, un manual de protocolo para tratar al cliente.

3. Porque debemos encontrar una ventaja competitiva. Estamos hablando de un negocio, por lo que el Protocolo es un sumando para poder conseguir que haya una diferenciación a la hora de conseguir mejores resultados y mejor imagen.

4. Porque esta diferenciación no solo radica en el precio del producto o servicio. Al final, cuanto mejor sea nuestro protocolo, nuestro trato a los clientes, mejor podremos redundar y ajustar los precios de cara a la clientela.

5. Porque son las relaciones y las experiencias las que al final brindan la diferenciación del resto.

Especialmente en el sector hotelero, diferenciándose aunque dentro del turístico, hay que brindar valores agregados como buena imagen, atención personalizada, soluciones individuales, brindar un valor diferencial, un plus que atraiga al consumidor y le brinde una experiencia de consumo más satisfactoria que la que tendría con la competencia. 
La idea es diferenciarnos a la hora de dar el producto que damos, en este caso el Turismo, y el protocolo aplicado a ese mundo del sector turístico.

Un eslabón fundamental en la cadena lo constituye el profesional del turismo/hotelería si se tiene en cuenta que el objeto de este profesional está también constituido por las actividades de turismo, viajes y hospitalidad. En el Turismo tenemos un gran componente de interculturalidad, ya no solo desde el punto de vista de que tenemos gente que trabaja de diferentes culturas (asiática, caucásica, hispana, musulmana...), y tenemos que tener un protocolo para ellos, de relaciones internacionales entre ellos, porque cada uno tiene sus costumbres. Lo mismo ocurre para poder tratar las diferentes culturas que nos vienen como clientes, en un hotel como huéspedes. Importantísimo. Si nos viene un musulmán que practica su religión tenemos que darle una habitación orientada hacia donde él precisa, o un sitio para que ore. Todo eso entra en el protocolo de las relaciones interculturales que debe tener el Turismo en la hotelería.

Procesos de desarrollo, gestión de servicios, atención a residentes o clientes, así como el sistema de interrelaciones que ello genera, sin olvidar las relaciones propias entre el staff. Concretamente, en Hispanoamérica, donde el turismo es un borboteo constante durante todo el año, hace falta que haya un Jefe de Protocolo o de Relaciones Internacionales como mínimo para que atienda todas esas necesidades de las personas que tenemos bajo nuestra tutela trabajando, de diferentes pensamientos, credos, religiones y culturas. Es muy complicado. Si contamos con una persona de protocolo o de relaciones internacionales, nos va a favorecer muchísimo, y es algo que se obvia hoy en día. Primero hay que pensar en la calidad de lo que hay dentro. Si el equipo de trabajo no funciona al cien por cien, mal servicio podremos dar a los clientes, de los que vive el sector. A mejor trato, mejor protocolo, mejor afluencia de clientes. Mejor márquetin de vox populi. A peor protocolo, peores maneras, menos clientela.

El protocolo en la empresa turística se establece desde tres componentes importantes:

1. El protocolo como individuos. A las personas que tenemos hay que tratarlas con un protocolo individualizado, personalizado. 
2. El protocolo con nuestro equipo más cercano y con el resto de los departamentos. Por ejemplo, un hotel se divide en plantas, las camareras, los botones, el lobby, el recepcionista, y para todo eso hay que tener protocolos diferenciados, aparte del que homogeneice todo.

3. El protocolo con nuestros clientes.

Los principios importantes en el Protocolo son:

10 El principio de la Cortesía Internacional. El turismo es internacional aunque sea dentro de nuestras fronteras. Tenemos muchos turistas que vienen de fuera, por lo que debe ser a nivel internacional.

2o Es una útil guía, un manual para el trabajo, constante.

30 Habilidades de competencia en las actuaciones. Nos dice cómo debemos actuar y tomar resoluciones y decisiones en un momento determinado.

40 Imagen de la institución. El protocolo siempre es imagen. En Turismo es muy importante. Nuestro país es de los mejores, pero la imagen que dan muchas de nuestras instituciones dedicadas al turismo no es la mejor por la falta de los profesionales que deben dedicarse al protocolo.

En el Protocolo turístico y hotelero tenemos:

- El recibimiento a clientes (huéspedes). Hay que saber a qué segmento turístico nos dirigimos. En todos los hoteles nos vamos a encontrar siempre con personas relevantes, vips, unas de incógnito a nivel institucional, y otras a nivel farándula, encantados de recibir pleitesía. Tenemos que tener un protocolo para cada uno.

- Hospitalidad, comunicación con los huéspedes (clientes). El trato por teléfono a clientes/huéspedes y distribuidores. La persona que está en la recepción o la que está en compras necesita un protocolo, pero no de gestión logística e infraestructuras como se cree la gente, sino un protocolo para los distribuidores del sector turístico, que son muy complicados. Por culpa de un mal distribuidor o de un mal trato, en algún momento, podría no llegarnos el producto a tiempo para abastecer nuestro hotel, resort, nuestra agencia y, sobre todo, a nuestros demandadores, los clientes, de ese producto. 
Es muy importante el Turismo/Hotelería de eventos. Los eventos, ahora de moda, siempre han existido. Son parte esencial y prioritaria del protocolo, por lo que hay ferias, fórums, congresos, etc. a nivel turístico. Los países que más turismo hacen gracias a los eventos que realizan son Francia y Tailandia. Sobre todo Asia empieza a brillar por su gestión turística y a nivel de congresos, aunque esté un poco atrás por la lejanía.

Las diferencias en el segmento social aluden a hoteles, resorts, turismo rural, turismo deportivo, turismo de aventura o multiaventura, INSERSO, grupales y colectivos, que no son lo mismo. Los establecimientos hoteleros tienen una relación muy directa con sus clientes, bien sea en un hotel, restaurante, cafetería, o en cualquier otro tipo de establecimiento. Es necesario conocer las reglas básicas de etiqueta para saber tratar a los clientes.

Desde siempre se tiende a creer que el protocolo en el Turismo es básicamente de hostelería, y nada más erróneo. Es una parte del Protocolo, y abarca mucho más. Es un mundo en sí mismo. Los viajes, los cruceros, los hoteles, las agencias de viajes, los congresos y convenciones (eventos específicos del sector), los clientes (individual, grupal o colectivo), los restaurantes, y mucha aplicación de protocolo internacional, etiqueta y protocolo de empresa, entre otros.

Para mí, ya ultimando, el protocolo turístico es una profesión y un arte convertido en pasión. 